\title{
Lead Poisoning in Young Children
}

\author{
By HUNTINGTON WILLIAMS, M.D., EMANUEL KAPLAN, Sc.D., \\ CHARLES E. COUCHMAN, and R. R. SAYERS, M.D.
}

Lead poisoning in young children associated with eating lead-containing paint has been increasingly recognized until it ranks as one of the most common causes of child mortality due to poisoning. However, lead poisoning is not a reportable disease and, therefore, there is a lack of adequate morbidity data (1). The widespread occurrence of lead poisoning throughout the United States and Canada is evident from reports of cases in which eating lead-containing paints was mentioned as the cause of poisoning in infants and young children (2-37). Although 19 different communities are mentioned, most of the cases were from large cities such as Baltimore and Boston, where children's hospitals or local health authorities were especially interested in the problem. During the period $1931-40$, the city of Baltimore alone reported 24.3 percent of all the child deaths from lead poisoning reported from the entire United States registration area (1). From January 1, 1931, to June 30, 1951, a total of 293 cases of lead poisoning was reported in Baltimore children. Of these, $83 \operatorname{died}(\mathscr{2})$.

The most common cause of lead poisoning is

Dr. Williams is commissioner of health of the Baltimore City Health Department; Dr. Kaplan is chief of the division of chemistry; $\boldsymbol{M r}$. Couchman is director of the bureau of industrial hygiene; and Dr. Sayers, a medical director (retired) of the Public Health Service, is senior medical supervisor of occupational diseases. For several years he was director of the Bureau of Mines, Department of the Interior. apparently the habit of chewing paint from cribs, toys, furniture, woodwork such as window sills, and the eating of painted plaster and fallen paint flakes. The tendency to put things in the mouth, though normal in the first year of life, is considered abnormal if continued into the latter part of infancy, and is referred to as pica, or perverted appetite $(6,30)$. Pica is the usual forerunner of lead poisoning.

Although pica does not exist on a seasonal basis, a striking number of lead-poisoning cases resulting from this habit occur in the hot summer months. For this, no satisfactory explanation is available, although several investigators have commented on the tendency for lead poisoning to occur in children during the warmer weather $(\mathscr{2}, 21,26,37-40)$.

\section{Diagnosis, Prognosis, and Sequelae}

Unrecognized plumbism, lead poisoning, in children may explain many obscure nervous conditions and convulsions of undetermined etiology $(12,22)$. Errors have been made in operating on cases presenting symptoms indicating a need for surgery but which were caused by lead intoxication $(14,31)$.

Lead poisoning is cumulative. Some weeks or months following the continued ingestion of small amounts of lead, symptoms begin to appear. Early symptoms may be only irritability, fretfulness, or disturbed gastrointestinal function characterized by lack of appetite, constipation, vomiting, or cramps. A secondary anemia with resulting pallor is often present. More severe intoxication results in lead en- 
cephalitis due to increased intracranial pressure because of cerebral edema. The acute stages of the disease are manifested in changes in mental state, ataxia, persistent vomiting, muscle weakness or paralysis, delirium, stupor, coma, convulsions, and, not infrequently, death.

Diagnosis involves correlation of a history of paint-eating or pica with the physical findings, laboratory and X-ray data. The importance of eliciting a history of pica cannot be overemphasized in the early recognition of the disease. Examination of blood smears often shows stippling of the red blood cells. Porphyrinuria is frequently found. The demonstration by roentgenogram of an increased density in the growing ends of the long bones is a cardinal sign of lead poisoning (34). In recent years, the quantitative determination of lead in blood or urine as an index of abnormal lead absorption has proved an invaluable aid in diagnosis $(41,42)$. Lead poisoning in children differs considerably from the disease in adults. Central nervous system involvement or encephalopathy, rarely seen in adults, is common in children, whereas peripheral neuritis, lead line on the gums, and colic are usually absent.

The prognosis in lead encephalitis in children is poor; the high mortality rate, as well as the incidence of severe, lifelong, residual nervous system injury, has been commented on by many investigators (25). The mental development of even the less severe cases may be seriously impaired (16).

\section{Baltimore Experience}

Thomas and Blackfan (3) of the Johns Hopkins Hospital were the first to point out in American pediatric literature the frequency of occurrence of lead encephalopathy in children. Subsequently, studies at the same institution provided pioneer information on the diagnosis $(4,26,34,42)$ and treatment $(25,40)$ of plumbism in infancy. The Baltimore City Health Department in 1932 began studies of nonindustrial lead poisoning in children in an investigation of cases resulting from the use of storage battery casings for fuel (43). Afterwards, all cases of lead poisoning brought to the attention of the department were routinely investigated to ascertain the source of the lead.

\section{Blood-Lead Laboratory Service}

As an aid in diagnosis, since early in 1935 , the bureau of laboratories of the Baltimore City Health Department has maintained a free routine analytical service for the quantitative estimation of lead in the blood of cases of suspected plumbism (41). The dithizone method is used. Especially prepared lead-free blood specimen collection containers known as "bloodlead outfits" are distributed to the local hospitals and physicians in the same manner as outfits regularly provided for specimens in cases of communicable diseases.

Since 1935, almost 3,000 specimens of blood from about 1,800 children have been tested for lead. Increase in this service, as well as the increased number of cases diagnosed during the last 4 years in contrast to the preceding 13 years, is shown in the accompanying table. Undoubtedly, the improved educational activities in lead poisoning prevention in recent years have been a prominent factor in this increase.

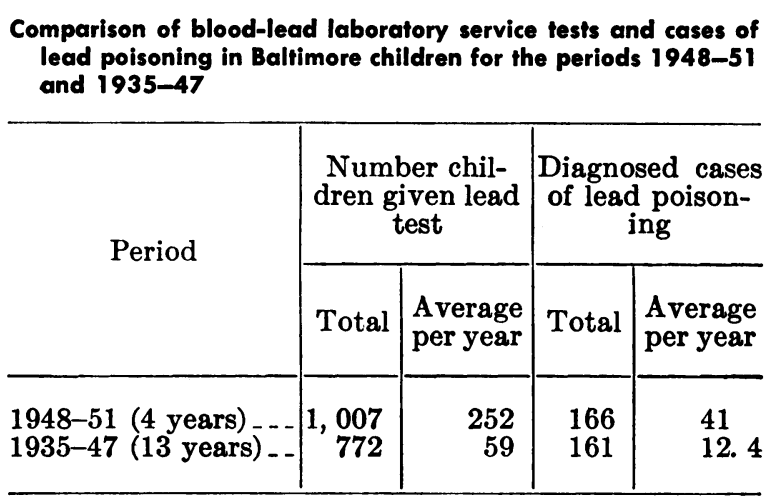

\section{Field Investigation}

Field work, associated with a follow-up of the blood-lead laboratory service, has enabled the Baltimore City Health Department to acquire relatively accurate data concerning the incidence of lead poisoning in the community (1). A report of each blood analysis was forwarded to the bureau of industrial hygiene, which investigated cases in which the blood showed an abnormal absorption of lead. The 


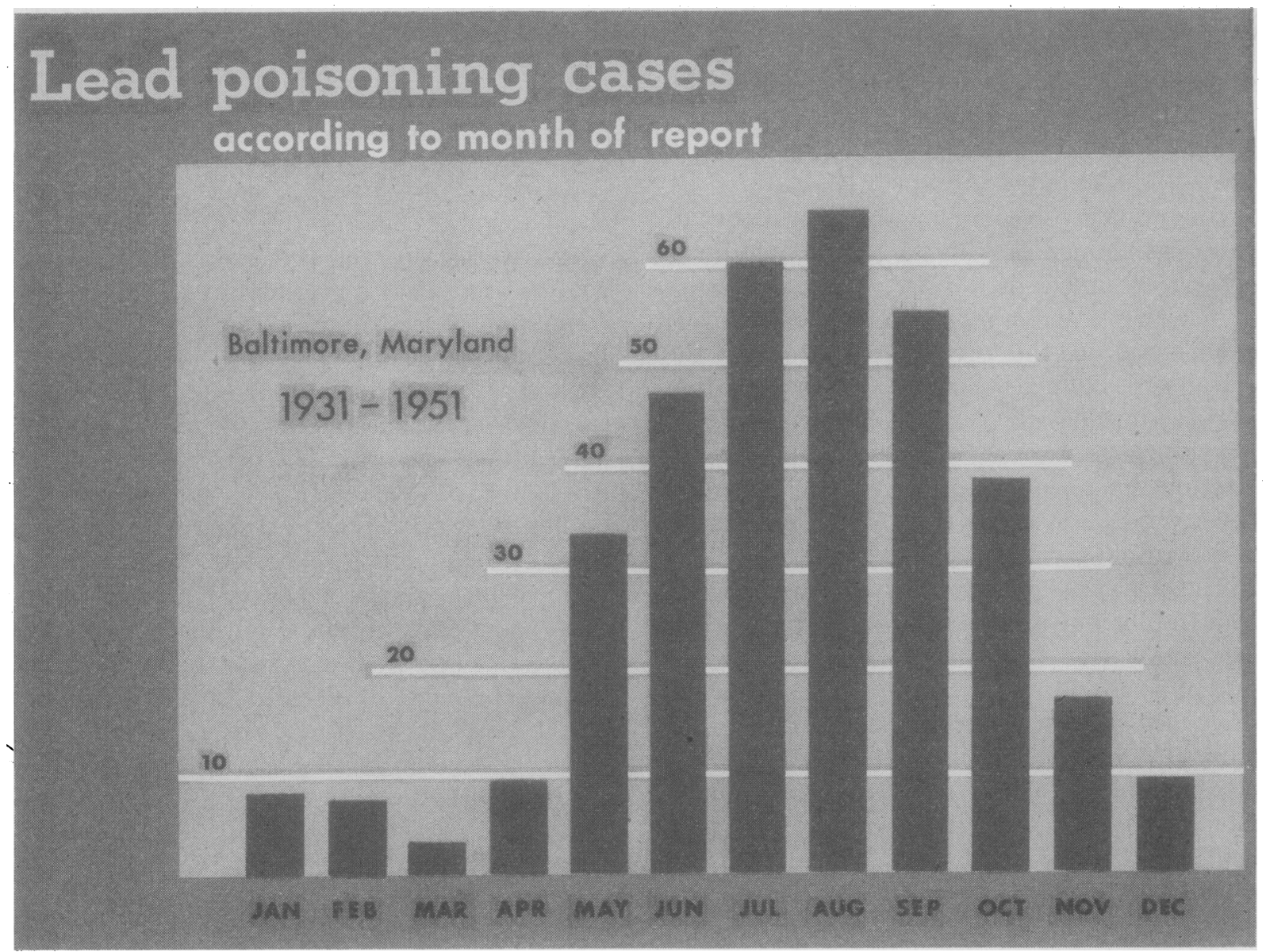

Figure 1. Lead poisoning cases reported in Baltimore, according to month of report, 1931-51.

upper limit of normal is considered to be 0.05 to $0.06 \mathrm{mg}$. percent of lead. Adequate clinical and laboratory data were usually available because nearly all of the children were diagnosed and treated in hospitals.

After learning the medical history, a field worker visited the home of the affected child to obtain pertinent information, particularly concerning exposure to lead. Almost without exception, the cause of poisoning was found to be pica associated with the ingestion of paint. This was confirmed at the time of the home visit by obtaining for analysis a sample of paint scrapings, approximately 0.5 to $1 \mathrm{gm}$., from surfaces where the child had chewed paint.

\section{Lead Poisoning in Children}

Over the past two decades, 347 cases of lead poisoning have been diagnosed in Baltimore children. These do not include the storage battery cases referred to earlier. Of the 347 cases, 54 have been reported since June 30, 1951. A study of these cases has led to the discovery of interesting patterns in the seasonal incidence of the disease, age and color distribution of the children, and the types of houses involved. It is evident from figure 1 that more cases were reported in July and August than in any other months. There was no significant difference in incidence between sexes. Sixty percent of the cases occurred among children in their second year of life, at teething age, when they have a greater tendency to put things into the mouth. Only 2.3 percent of the cases were in children above 5 years of age.

The annual attack rate for the age segment under 5 years during the period 1931-51 was 7.5 times as high among the Negro population (71 per 100,000) as it was among the white 
population (9.5 per 100,000$)$. When the more recent experience of the past 4 years is considered, the attack rates for both white and Negro children as well as the difference between races are significantly elevated above the average experience cited. The high rates among Negro children are a problem of considerable public health significance since 30 percent of Baltimore's preschool population is Negro. The racial difference in incidence is believed to be due to environmental factors probably resulting chiefly from economic disadvantage.

For the past few years information has been collected on home ownership in neighborhoods where child lead poisoning cases occurred. Almost 90 percent of the houses were tenantoccupied. In the early years of the study some of the cases arose in well-kept property, but with the continued community education by press and radio, cases in this category have become relatively rare. The problem in Baltimore at present involves chiefly slum or blighted-area properties. The cases are concentrated in two areas which are of known slum status and where the houses are old and have had many coats of paint, usually lead paint, applied throughout several decades. A typical home where a case of lead poisoning occurred is shown in figure 2.

\section{Methods of Prevention}

\section{Education and Publicity}

In an effort to prevent lead poisoning, repeated public warnings about this child health hazard have been given by the Baltimore City Health Department in the press, by radio, and on television. The Baltimore Health Newsmailed each month to over 10,000 persons, including 1,800 local physicians and 6,000 school teachers-devoted a number of issues ( 2,46 , $47)$ to the subject. The bureau of child hygiene issued a leaflet (45) entitled "Lead Poisoning in Children, a Disease You Can Prevent." The leaflet directs attention to 220 cases and 78 deaths from lead poisoning in Baltimore during the past 18 years, makes suggestions to parents for preventing children from contracting the disease, lists the warning sig- nals to be watched for, and stresses the importance of early diagnosis and treatment.

It is not unusual now for a mother to take a child to a physician and to volunteer information on pica and suggest that the child may be suffering from lead poisoning.

\section{The Public Health Nurse}

One of the most promising advances in the prevention of child plumbism was the assignment several years ago of a public health nurse supervisor to investigate lead poisoning cases. With the knowledge gained by intimate association with the problem, the supervisor was able to interest other public health nurses. They not only make home visits and disseminate information in the most-affected areas of the city, but may take part in well-baby clinics, where mothers are told of the dangers connected with pica.

\section{Lead Paint Removal}

For the past 4 years, landlords of properties where lead poisoning has occurred have been notified, in accordance with the Baltimore ordinance on the hygiene of housing (44), to remove lead paint from the surfaces where there is flaking or where a child has chewed. Of 96 such notices during this period only 2 were not complied with in the time allotted. Both owners were summoned to the Magistrate's Court, where they were found guilty and fined; only then did they fully comply with the health department's orders. Many sanitarians on the health department staff who inspect property, primarily on the basis of other types of complaints or because of rodent and housing surveys, also require correction of a flaking paint condition in the notice sent to the property owner. The sanitarians are instrumental in the distribution to slum dwellers of the leaflet on the lead poisoning prevention (45).

\section{Legislation:}

Because of the danger to small children, manufacturers of cribs and toys have for many years $\left(9,1^{1 \%}, 48\right)$ used paints free of lead pigment.

For various reasons legislation against the use of lead paint has existed in widely separated jurisdictions for a number of decades. Germany has had a national law on the matter 


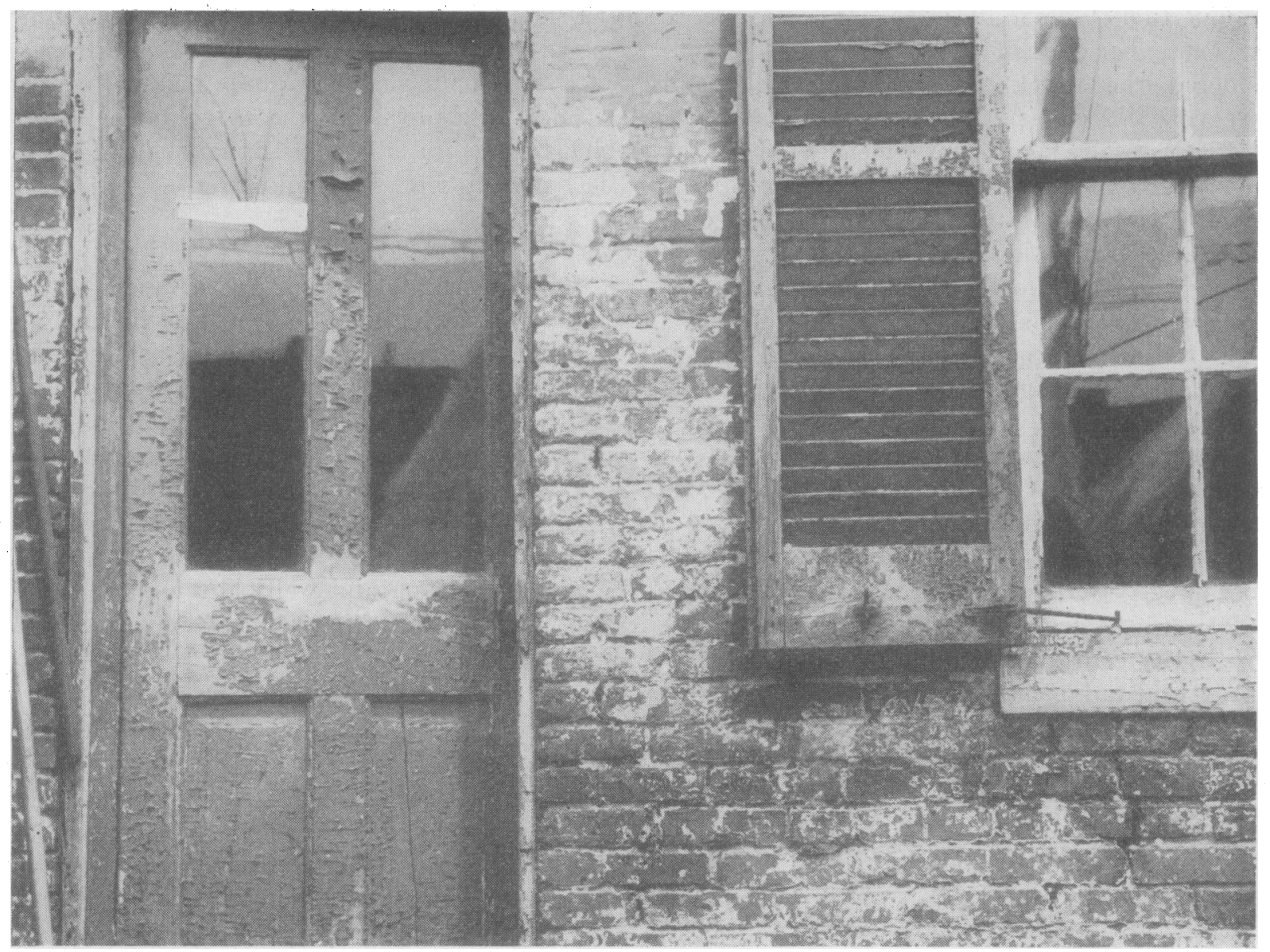

Figure 2. House doorway in home of patient with lead poisoning.

since about 1900. Regulations prohibiting the use of lead-containing paints on toys, children's furniture, and for interior work have been enforced in France since 1917 (17). As early as 1922, the nations adhering to the International Labor Office in Geneva proposed a convention prohibiting the use of white-lead paint in interior painting of buildings as a health measure affecting painters (49). Since 1932, factory legislation in Ontario has required all leadcontaining paints supplied to plants manufacturing children's toys and furniture to be so labeled $(17,48)$. No cases of lead poisoning related to chewing on new furniture or painted toys have been reported in recent times. When such objects are involved, the source of lead has been repainted furniture-parents frequently use lead-base paints for repainting jobs. Nevertheless, the Maryland State Legislature in 1949 enacted chapter 517 of the Acts of 1949, which made it compulsory to affix a label to any toy or to any children's furniture decorated with paint or other material containing lead or any other poisonous substance, stating clearly the poisonous nature of the paint or decoration. Unenforceable, the law was repealed a year later.

On June 27, 1951, regulation No. 17 was adopted by the commissioner of health of Baltimore under the ordinance on the hygiene of housing. The text follows:

Interior Painting. No paint shall be used for interior painting of any dwelling or dwelling unit or any part thereof unless the paint is free from any lead pigment.

The wording was studied carefully so as not to prohibit the use of paints containing either lead driers, usually present in amounts corresponding to less than 1 percent of lead in the finished paint, or pigments contaminated with 
traces of lead. The use of the term "lead-free paint" was purposely avoided, since it is doubtful if the usual commercial product could be made without having a detectable amount of lead present. This regulation has had pronounced salutary effect as shown by an increasing interest on the part of home owners, health agencies, and local paint manufacturers, some of whom have recently advertised paints free from lead pigment.

\section{Lead Content of Paint}

The health department's suggestions to parents interested in the purchase of "leadfree" paint emphasizes a selection based upon the labeled composition of the product. Although there is no Maryland law on the subject, many of the paints sold locally contain a statement of composition on the label. Such labels provide information on the presence of leadbearing compounds and are adequate except in those instances where the terms "chrome yellow," "chrome green," or "chrome orange" camouflage the fact that these pigments contain substantial amounts of lead chromate. For this reason, when inquiry is made, it has been recommended that no yellow, green, or orange colors be used in refinishing articles of furniture intended for use by children unless the pigment composition as declared on the label clearly excludes the presence of lead.

\section{Summary}

Lead poisoning in children caused by ingesting lead from surfaces coated with leadcontaining paint is apparently widespread throughout many parts of the Nation.

The disease has a high rate of incidence in the city of Baltimore, where it occurs in children of teething age living in old, run-down rented properties where lead paint had been used indoors for many years.

Public health education, coupled with a "lead consciousness" on the part of physicians and the pediatric clinics of local hospitals, and with a blood-lead laboratory service offered by the city health department has resulted in a marked increase in case recognition.

It is hoped that the application of principles involving education and the enforcement of measures regulating the use of lead-containing paints will result in a material reduction and the eventual eradication of child lead poisoning in Baltimore City.

\section{ACKNOWLEDGMENTS}

The authors are indebted to Matthew L. Taback, director of the bureau of biostatistics, and to Margaret Galbreath, supervisor assigned by the bureau of public health nursing to the bureau of industrial hygiene, for assistance in the preparation of this article.

\section{REFERENCES}

(1) McDonald, J. M., and Kaplan, E.: Incidence of lead poisoning in the city of Baltimore. J. A. M. A. 119: 870-872 (1942).

(2) Williams, Huntington: Lead poisoning killed 83 children. Baltimore Health News 28: 113-116 (1951).

(3) Thomas, H. M., and Blackfan, K. D. : Recurrent meningitis due to lead in a child of flve years. Am. J. Dis. Child. 8: 377-380 (1914).

(4) Blackfan, K. D.: Lead poisoning in children with especial reference to lead as a cause of convulsions. Am. J. Med. Sc. 153: 877-887 (1917).

(5) Strong, R. A.: Meningitis caused by lead poisoning in a child of nineteen months. Arch. Ped. 37: 532-537 (1920).

(6) Ruddock, J. C. : Lead poisoning in children with special reference to pica. J. A. M. A. 82: 1682-1683 (1924).

(7) McKhann, C. F.: Lead poisoning in children. Am. J. Dis. Child. 32: 386-392 (1926).

(8) McKhann, C. F.: Lead poisoning in children. The cerebral manifestations. Arch. Neurol. Psychiat. 27: 294-304 (1932).

(9) McKhann, C. F., and Vogt, E. C.: Lead poisoning in children. J. A. M. A. 101:1131-1135 (1933).

(10) Donnally, H. H., Schutz, C. A., and Nimetz, A.: Chronic lead poisoning in early childhood. Virginia Med. Monthly 62: 83-89 (1935).

(11) Nicholson, W. W.: Lead poisoning in children. Kentucky Med. J. 33: 180-181 (1935).

(12) Cushing, H. B.: Diagnosis of lead poisoning in children. Internat. Clin. 44th Series 1: 189-195 (1934).

(13) Gant, V. A.: Lead poisoning. Chicago, Industrial Health Book Co., 1939, pp. 39-42.

(14) Bucy, P. C., and Buchanan, D. N.: The simulation of intracranial tumor by lead encephalopathy in children. J. A. M. A. 105: 244-250 (1935).

(15) Kowaloff, I. : Lead encephalopathy. Am. J. Dis. Child. 61: 547-556 (1941). 
(16) Byers, R. K., and Lord, E. E.: Late effects of lead poisoning on mental development. Am. J. Dis. Child. 66: 471-494 (1943).

(17) Ross, R. J., and Brown, A. : Poisonings common in children. Canad. Pub. Health J. 26: 237-243. (1935).

(18) Parker, G. M. (Division of Industrial Hygiene, Toronto): Personal communication.

(19) Taylor, H. W., and Schram, M.: Abdominal symptoms of lead poisoning in children. Arch. Ped. 53: 182-186 (1936).

(20) Anonymous: Lead toys-lead paint-lead poisoning. Safety Education 22 : 74 (1942).

(21) Rapoport, M., and Rubin, M. I. : Lead poisoning. A chemical and experimental study of the factors influencing the seasonal incidence in children. Am. J. Dis. Child. 61: 245-255 (1941).

(22) Netzley, R. E.: Lead encephalitis precipitated by acute infection. California West. Med. 46: 306-308 (1937).

(23) Golden, J. T.: Watch out for lead poison. The Cincinnati Inquirer, Sunday, August 12, 1951, p. 3.

(24) Goettsch, E., and Mason, H. H.: Glycosuria in lead poisoning. Am. J. Dis. Child. 59: 119-128 (1940).

(25) Ennis, J. M., and Harrison, H. E. : Treatment of lead encephalopathy with BAL (2,3-dimercaptopropanol). Pediatrics 5: 853-868 (1950).

(26) Blackman, S. S., Jr. : The lesions of lead encephalitis in children. Bull. Johns Hopkins Hosp. 61: 1-61 (1937).

(27) Dannenberg, A. M., Widerman, Arnold H., and Friedman, Paul S. : Ascorbic acid in the treatment of chronic lead poisoning. J. A. M. A. 114: 1439-1440 (1940).

(28) Haverfield, W. T., Bucy, Paul C., and Elonen, Anna S.: The surgical treatment of lead encephalopathy. J. A. M. A. 114: 2432-2437 (1940).

(29) Wilkinson, E. E.: Sodium citrate in treatment of lead encephalopathy. Texas State J. Med. 43: 442-445 (1947).

(30) Stetson, C. A.: Pica: Its relationship to lead poisoning in children. J. Maine Med. Assoc. 38: 10-12 (1947).

(31) Sibley, W. L. : Lead poisoning in infancy. A case in which two operations were performed on the stomach. 'South. Surgeon 15: $427-436$ (1949).

(32) Akelaitis, A. J.: Lead encephalopathy. A clinicopathological study. J. Nerv. \& Ment. Dis. 93: 313-331 (1941).
(33) McGovern, J. P., and Simmons, E.: Chronic lead poisoning associated with eosinophilia and splenomegaly. Clin. Proc. Child. Hosp. 6: 33-38 (1950).

(34) Park, E. A., Jackson, Deborah, and Kajdi, Laslo: Shadows produced by lead in the $X$-ray pictures of the growing skeleton. Am. J. Dis. Child. 41: 485-499 (1931).

(35) Seifert, H. E. (Virginia Bureau of Industrial Hygiene) : Personal communication.

(36) McKhann, C. F.: Lead poisoning. In Brennemann's Practice of Pediatrics, Hagerstown, Md., W. F. Prior Co., Inc., 1948, vol. 1, ch. 18, p. 1-8.

(37) Feldman, H. T. : Lead poisoning. Salient features in its diagnosis and treatment. Clin. Proc. Child. Hosp. 7: 194-205 (1951).

(38) Brienl, A., and Young, W. J.: The occurrence of lead poisoning among North Queensland children. Ann. Trop. Med. 8: 575-589 (1914-15).

(39) Fukushima, M., and Matsumato, H.: Statistics of 298 cases of infantile lead poisoning. Oriental J. Dis. Infants 3 : 27-31 (1928).

(40) Shelling, D. H., and Hopper, K. B.: Calcium and phosphorus studies. Bull. Johns Hopkins Hosp. 58: 137-211 (1936).

(41) Kaplan, E., and McDonald, J. M.: Blood-lead determinations as a health department laboratory service. Am. J. Pub. Health 32: 481-486 (1942).

(42) Blumberg, H., and Scott, T. F. Mc.: The quantitative spectrographic estimation of blood lead and its value in the diagnosis of lead poisoning. Bull. Johns Hopkins Hosp. 56: 276-293 (1935).

(43) Williams, Huntington, Schulze, W. H., Rothchild, H. B., Brown, A. S., and Smith, F. R., Jr. : Lead poisoning from the burning of battery casings. J. A. M. A. 100 : 1485-1489 (1933).

(44) Baltimore ordinance on the hygiene of housing. No. 384, approved March 6, 1941, as amended by No. 902, approved March 29, 1943.

(45) Lead poisoning in children-A disease you can prevent. Baltimore City Health Department Leaflet, 1949.

(46) Lead poisoning in children. Baltimore Health News 14: 109-110 (1937).

(47) Lead poisoning in children is preventable and can be fatal. Baltimore Health News 26: 122124 (1949).

(48) Jephcott, C. M.: Lead in certain colored chalks and their danger to children. Canad. Pub. Health J. 28 : 391-393 (1937).

(49) Hamilton, Alice: Recent changes in the painters trade. U. S. Department of Labor, Division of Labor Statistics, Bulletin .No. 7, 1937, p. 40. 